\title{
Technical note: Improved methodology for analyses of acid detergent fiber and acid detergent lignin
}

\author{
E. Raffrenato and M. E. Van Amburgh ${ }^{1}$ \\ Cornell University, Ithaca, NY 14853
}

\begin{abstract}
The objective of this study was to evaluate the methodology of the acid detergent lignin (ADL) assay in an effort to evaluate particle loss, improve repeatability, and decrease variation within and among samples. The original ADL method relied on asbestos as a filtering aid, but that was removed in 1989 with the mandate from the Environmental Protection Agency to eliminate asbestos in the environment. Furthermore, recent work on fiber methodology indicated that pore size in the Gooch sintered glass crucible $(40-60 \mu \mathrm{m})$ was too large to trap all of the small particles associated with neutral detergent fiber (NDF) and acid detergent fiber (ADF). Thus, any loss of ADF could potentially result in a loss of ADL. Sixty forages including conventional and brown midrib corn silages, alfalfa silages and hays, mature grasses, early vegetative grasses, and 9 feces samples, were analyzed sequentially for ADF and ADL as outlined in the 1973 procedure of Van Soest except for the use of the asbestos fiber. A glass microfiber filter with a $1.5-\mu \mathrm{m}$ pore size was chosen as a filtering aid because it met the criteria required by the assay: glass, heat resistant, acid resistant, chemically inert, and hydrophobic. To compare with the current ADF and ADL assays, the assays were conducted with either no filter or the glass filter inserted into crucibles, rinsed with acetone, and then according to the 1973 procedure of Van Soest. The samples analyzed covered a range from 18.11 to $55.79 \% \mathrm{ADF}$ and from 0.96 to $9.94 \%$ ADL on a dry matter (DM) basis. With the use of the filter, the mean ADF values increased $4.2 \%$ and mean ADL values increased $18.9 \%$. Overall, both $\mathrm{ADF}$ and $\mathrm{ADL}$ values were greater with the use of the glass microfiber filter than without, indicating that as the type of sample analyzed changed, use of the Gooch crucible without the filtering aid results in particle loss. The adoption of the use of a small pore size $(1.5 \mu \mathrm{m})$ glass microfiber filter to improve filtration and recovery
\end{abstract}

Received August 9, 2010.

Accepted March 27, 2011.

${ }^{1}$ Corresponding author: mev1@cornell.edu of $\mathrm{ADF}$ and $\mathrm{ADL}$ and to reduce variation in the $\mathrm{ADL}$ assay is recommended, especially when sintered glass bottom crucibles are used. These differences in recovery and repeatability have implications for other fiber and lignin methods, as well as for estimating the potential changes in digestibility of fibrous feeds and feed quality. Key words: acid detergent fiber, acid detergent lignin, filtration

\section{Technical Note}

Since the 19th century, lignin has been defined within plant tissues as a chemical entity or described by the functional role that lignin has in the plant (Van Soest, 1994). For the nutritionist, it has been important to know the lignin value of a feed and forage because it is generally accepted that lignin and lignin cross-linking to carbohydrates are the primary factors responsible for limiting the ruminal and intestinal digestion of forages (Besle et al., 1994; Van Soest, 1994)

Several well-defined procedures to quantify lignin in plant tissues have been developed and approved by AOAC (Hatfield and Fukushima, 2005). The most commonly used method in ruminant nutrition and agronomy is the procedure developed by Van Soest (1973). A sample undergoes an acid detergent extraction step, producing ADF, and then a subsequent and sequential step that isolates the lignin from the ADF through the use of $72 \%$ sulfuric acid in hydrolyzing the remaining carbohydrates. Of all procedures for measuring lignin, acid detergent lignin (ADL) results in the lowest values of lignin, as reviewed by Hatfield and Fukushima (2005), from 2 to 5 times lower than Klason lignin values (Jung et al., 1999).

Inconsistencies exist in the ability to measure lignin quantitatively (Fahey and Jung, 1983; Cochran et al., 1988) with observed positive and negative recoveries (Fahey and Jung, 1983; Van Soest, 1994). The original and sequential AOAC lignin procedure for crucibles (Van Soest and Wine, 1967; Van Soest, 1973) relied on the use of asbestos fiber as a filtering agent, but asbestos was rendered a health hazard in 1989 by the United States Environmental Protection Agency (EPA, 
1989) and removed. The sintered glass filter within the crucible is prone to particle loss and plugging with fine particles. Since the removal of asbestos from the procedure, no other filtering aids have been used and none are as inert as asbestos (Van Soest, 1973). Udén (2006) evaluated the use of filtration or centrifugation to study the recovery of NDF and ADF by testing the use of a filter paper with porosity of $6 \mu \mathrm{m}$ or centrifugation at $9,000 \times g$ for 5 min against sintered glass crucibles with 2 levels of porosity (40-100 or 100-160 $\mu \mathrm{m}$ ) for feed and feces or in vitro residues, respectively. In that evaluation, the recovery of ADF was, on average, 20 and $24 \%$ higher for centrifugation and paper filtration, respectively, for both feeds and feces compared with the traditional sintered glass crucible (Udén, 2006).

In the paper by Udén (2006), ADL recovery was not evaluated, but it seems apparent that any change in recovery of ADF could affect the recovery of ADL. Our hypothesis was that ADL was lost both during the ADF analysis, as shown by Udén (2006), and in the $72 \%$ sulfuric acid hydrolysis step. Furthermore, this loss would vary among forage families and type of sample because the different physicochemical structure of cell walls would result in specific particle size reduction during the 2-step procedure that would pass through the sintered glass of a crucible. Smaller particles that result from the detergent and hydrolysis steps could be small enough to escape the $40-$ to $60-\mu \mathrm{m}$ pore size sintered glass filter.

Currently, glass microfiber filters are available that are manufactured from $100 \%$ borosilicate glass that is binder free and chemically inert, with pore sizes that extend into the sub-micron range, resulting in retention of very fine particles, and are relatively hydrophobic (Whatman Limited, GE Healthcare, Piscataway, NJ). Furthermore, these filters can be used at temperatures up to $550^{\circ} \mathrm{C}$ to facilitate ashing. These characteristics of the glass microfiber filters appear to make them an ideal replacement for asbestos in the ADL assay and hold the potential of improving recoveries compared with asbestos.

The precision of gravimetric analyses is dependent upon the ability to produce repeatable weights, accurate to at least 0.05 to $0.1 \%$ of the respective components being determined. An acceptable filtering aid would be more hydrophobic than hygroscopic to minimize water holding and reduce potential bias in weighing step of the procedure. Hot weighing at $105^{\circ} \mathrm{C}$ is preferred over the use of desiccators to avoid biased weighing or variability that is unacceptable in the assay. In gravimetric fiber analysis, the residues from the various extractions and the glass crucibles themselves can be very hygroscopic, adsorbing several milligrams of water when allowed to cool to room temperature. Because most samples or residues are usually $500 \mathrm{mg}$ or less, absorbed water can result in substantial measurement error; thus, any filtering aid needs to be evaluated for water-holding capacity.

Our hypothesis was that the removal of asbestos as a filtering aid increased the loss of ADF and ADL particles from those samples that were especially low lignin and highly processed, and that the addition of a microfiber filtering aid would increase particle recovery and reduce variation in the ADL assay.

Sixty forages, including conventional and brown midrib corn silages, alfalfas, mature grasses (straws and hays), and early vegetative grasses, as well as 9 feces samples, were dried at $60^{\circ} \mathrm{C}$, ground through a $1-\mathrm{mm}$ screen using a Wiley mill (Thomas Scientific, Swedesboro, NJ), stored at room temperature in sealed plastic containers, and analyzed in duplicate for DM, ADF, and ADL using the procedure of Van Soest (1973), except that asbestos fiber was not used. Dry matter was measured by drying in a forced air oven at $105^{\circ} \mathrm{C}$ overnight. Crucibles with smaller porosity $(10-15 \mu \mathrm{m}$ and $4-5.5 \mu \mathrm{m}$ ) were tested for filtering ease, recovery, and repeatability, but resulted in greater filtering problems and increased variation and their use was abandoned. The filtering problems with smaller pore size crucibles are most likely due to differences in the 3 -dimensional structure of the fritted disc glass filters that allows smaller particles to be trapped, thereby decreasing filtration efficiency. This is implied in the AOAC NDF procedure that utilizes the coarse porosity (40-60 $\mu \mathrm{m})$ crucibles and describes filtering agents and cleaning methods for crucibles (Mertens, 2002). The filter 934-AH by Whatman (Whatman Limited; Whatman, 2009) was chosen as the filtering aid because it met the criteria required of the assay: glass, heat resistant, acid resistant, low water-holding capacity, and chemically inert. The 934-AH filters were inserted in 50-mL Pyrex Gooch crucibles with a porosity of 40-60 $\mu \mathrm{m}$ (Corning Life Sciences, Corning Inc., Lowell, MA) and rinsed with acetone. Crucibles with and without filters were tested for weight loss for their use in the ADF assay, the subsequent $72 \% \mathrm{H}_{2} \mathrm{SO}_{4}$ step, and ashing at $500^{\circ} \mathrm{C}$ in a muffle furnace. The mean weight loss averaged $0.02 \%$ and was not different for crucibles with and without filters. Other glass microfiber filters were evaluated (GF/A and GF/B, Whatman Limited) and although they met many of the criteria for use, the filters were partially destroyed during the $72 \% \mathrm{H}_{2} \mathrm{SO}_{4}$ step in the ADL assay. The filters were adequate for the ADF filtration procedure, but were not rigid enough to stay flat in the bottom of the crucible during the ADL assay and were not rigid enough to gently mix the acid 
and acid detergent residue. In addition, the GF filters did not survive the ashing process in a manner that ensured within-sample repeatability.

The intra-laboratory repeatability $\left(\mathbf{s}_{\mathbf{r}}\right)$ associated with a single analysis was determined by methods described by Wernimont (1990). Statistical results were determined for forage group and feces. The F-distribution was used to test the null hypothesis that replication variances were the same for the 2 procedures by calculating the $95 \%$ confidence limits for the ratio of the 2 variances. An interval including 1 would indicate that the 2 variances were similar. The Student's $t$-distribution was used to test the differences between the means (paired comparisons) of the 2 procedures $\left(d_{1}\right.$ and $d_{2}$ ) and the null hypothesis that the populations mean difference value of $d_{3}$ is zero. The null hypothesis was accepted if the $95 \%$ confidence interval included zero. For the probability distributions, evaluations were done within each forage group and feces using each group's degrees of freedom.

The samples analyzed ranged from 18.11 to $55.79 \%$ $\mathrm{ADF}$ and from 0.96 to $9.94 \%$ ADL on a DM basis. Evaluation of the filters for weight loss resulted in an average loss of $0.02 \%$ for the sequential procedure evenly distributed among the 3 steps. Blanks were used during this study to understand variation in weight and potential losses; however, the use of blanks in routine analyses would be considered useful but not necessary, especially if hot weighing was employed throughout the assay. To avoid variation in the assay, it was important to follow all the steps indicated by Van Soest (1973). This was especially true for the removal of the sulfuric acid during the rinsing step. Consistent with the original procedure, 2 additional washes with hot distilled water were necessary to ensure complete removal of the sulfuric acid from the sample and the filter paper, similar to the use of asbestos in the procedure. The hot weight of each crucible was measured at the lowest measured weight of the crucible (with or without sample), usually achieved between 20 and $30 \mathrm{~s}$ after removing the crucible from the oven. The presence of the filter resulted in the lowest weight at later times, specifically between 30 and $45 \mathrm{~s}$. This is likely due to the hygroscopic characteristics of the glass microfiber filter. The hygroscopic potential of the crucibles was not measured but the variation associated with the addition of microfiber filter was, and the variation in crucible weight increased approximately $0.05 \%$ when the microfiber filter was inserted and the hot-weighing method was employed. Therefore, more care and time are needed to record the most precise and accurate crucible weight when using microfiber filters. A desiccator was not used in our procedure, but the use of a desiccator at room-equilibrated temperatures might increase consistency when measuring a large number of samples and be applicable to a commercial laboratory or large volumes of samples.

Overall, mean ADF recovery was increased $4.2 \%$ and mean ADL recovery was increased $18.9 \%$ (Table 1 ). The change in ADF recoveries observed in this study were not as high as those observed by Udén (2006) but were of a similar magnitude given the range of samples used in this study. The differences in measured ADL were lowest for the alfalfas (Table 1), intermediate for grasses and wheat straw, and highest for the immature grasses, corn silages, and feces. Although the percentage difference in recoveries will appear inflated in low lignin samples, the differences in recoveries were not directly related to lignin content, thus implying variability due to forage type and possibly lignin structure. Overall, both ADF and ADL values were greater with the use of the microfiber filter than without $(P<0.05)$ indicating that, depending on the sample, use of the Gooch crucible without a filtering aid results in particle loss.

Repeatability standard deviations $\left(\mathrm{s}_{\mathrm{r}}\right)$ ranged from 0.07 to $0.29 \%$ for $\mathrm{ADF}$ and from 0.06 to $0.34 \%$ for ADL (Tables 2 and 3 ). The $\mathrm{s}_{\mathrm{r}}$ values obtained using the microfiber filters were similar to those obtained without the use of filters $(P>0.05)$ for both the ADF and ADL procedures for grasses, brown midrib corn silages, alfalfas, and immature grasses. However, the use of microfiber filters lowered the $\mathrm{s}_{\mathrm{r}}(P<0.05)$ for feces samples from 0.17 to $0.06 \%$ and from 0.23 to

Table 1. Percentage difference in recovery (range in parentheses) of ADF and acid detergent lignin (ADL) when using a glass microfiber filter (934-AH, Whatman, 2009) with 1.5- $\mu \mathrm{m}$ pore size for the ADF and ADL procedures, for different forages

\begin{tabular}{lcc}
\hline Group & ADF & ADL \\
\hline Grasses & $1.3(-0.5$ to 5.0$)$ & $10.1(-2.2$ to 19.3$)$ \\
Wheat straws & $0.1(-0.4$ to 0.7$)$ & $12.3(-1.16$ to 29.3$)$ \\
Immature grasses & $19.1(1.9$ to 11.1$)$ & $38.3(19.25$ to 90.5$)$ \\
Conventional corn silage & $3.3(-0.5$ to 9.9$)$ & $23.2(2.7$ to 41.0$)$ \\
Brown midrib corn silage & $7.0(-1.8$ to 15.1$)$ & $27.5(-1.5$ to 67.2$)$ \\
Alfalfas & $2.7(-1.0$ to 11.2$)$ & $3.2(-1.6$ to 10.1$)$ \\
Feces & $5.9(2.3$ to 10.3$)$ & $18.9(8.4$ to 32.0$)$ \\
\hline
\end{tabular}


Table 2. Intra-laboratory study results for the determination of ADF (\% of DM) per group of samples analyzed with and without the use of a glass microfiber filter (934-AH, (N) Whatman, 2009) with 1.5- $\mu \mathrm{m}$ pore size

\begin{tabular}{|c|c|c|c|c|c|c|c|c|c|}
\hline Group & $\mathrm{n}$ & $\begin{array}{c}\text { Avg. ADF } \\
\text { value } \\
\text { without filter }\end{array}$ & $\begin{array}{l}\text { Avg. ADF } \\
\text { value } \\
\text { with filter }\end{array}$ & $\begin{array}{l}\mathrm{RSD}^{1} \text { without } \\
\text { filter }\left(\mathrm{s}_{\mathrm{r}} 1\right) \\
\mathrm{g} / 100 \mathrm{~g}\end{array}$ & $\begin{array}{l}\text { CV of } \\
\mathrm{s}_{\mathrm{r}} 1, \%\end{array}$ & $\begin{array}{c}\text { Repeatability } \\
\quad \text { limit } \mathrm{r} \\
\left(\mathrm{r}=2.8 \times \mathrm{s}_{\mathrm{r}} 1\right)\end{array}$ & $\begin{array}{c}\text { RSD with } \\
\text { filter }\left(\mathrm{s}_{\mathrm{r}} 2\right) \text {, } \\
\mathrm{g} / 100 \mathrm{~g}\end{array}$ & $\begin{array}{l}\mathrm{CV} \text { of } \\
\mathrm{s}_{\mathrm{r}} 2, \%\end{array}$ & $\begin{array}{c}\text { Repeatability } \\
\quad \text { limit } \mathrm{r} \\
\left(\mathrm{r}=2.8 \times \mathrm{s}_{\mathrm{r}} 1\right)\end{array}$ \\
\hline Grasses & 6 & $44.30^{\mathrm{a}}$ & $44.80^{\mathrm{b}}$ & 0.27 & 0.62 & 0.62 & 0.31 & 0.7 & 0.7 \\
\hline Wheat straws & 5 & 54.22 & 54.26 & 0.31 & 0.59 & 0.88 & 0.18 & 0.35 & 0.53 \\
\hline Conventional corn silage & 12 & $22.76^{\mathrm{a}}$ & $23.66^{\mathrm{b}}$ & 0.24 & 1.09 & 0.69 & $\begin{array}{l}0.10 \\
0.29\end{array}$ & $\begin{array}{l}0.00 \\
1.25\end{array}$ & $\begin{array}{l}0.00 \\
0.82\end{array}$ \\
\hline Brown midrib corn silage & $\begin{array}{l}12 \\
11\end{array}$ & $20.81^{\mathrm{a}}$ & $22.29^{\mathrm{b}}$ & 0.11 & $\begin{array}{l}1.09 \\
0.53\end{array}$ & 0.53 & 0.1 & 0.48 & $\begin{array}{l}0.02 \\
0.48\end{array}$ \\
\hline Alfalfas & 16 & $28.41^{\mathrm{a}}$ & $29.13^{\mathrm{b}}$ & 0.29 & 1.02 & 0.81 & 0.35 & 1.2 & 0.97 \\
\hline Immature grasses & 10 & $27.09^{\mathrm{a}}$ & $28.85^{\mathrm{b}}$ & 0.11 & 0.56 & 0.31 & 0.09 & 0.5 & 0.27 \\
\hline Feces & 9 & $34.48^{\mathrm{a}}$ & $36.40^{\mathrm{b}}$ & $0.17 \dagger$ & 0.51 & 0.49 & $0.06 \ddagger$ & 0.17 & 0.17 \\
\hline
\end{tabular}

${ }^{\mathrm{a}, \mathrm{b}}$ Values within a row with different superscripts differ $(P<0.05)$.

${ }^{1}$ Repeatability standard deviation.

$\dagger †$ Pairwise comparison for RSD of the procedures differ $(P<0.05)$.

Table 3. Intra-laboratory study results for the determination of sequential acid detergent lignin (ADL, \% of DM) per group of samples analyzed with and without the use of a glass microfiber filter (934-AH, Whatman, 2009) with $1.5-\mu$ m pore size

\begin{tabular}{|c|c|c|c|c|c|c|c|c|c|}
\hline Group & $\mathrm{n}$ & $\begin{array}{c}\text { Avg. ADL } \\
\text { value } \\
\text { without filter }\end{array}$ & $\begin{array}{l}\text { Avg. ADL } \\
\text { value } \\
\text { with filter }\end{array}$ & $\begin{array}{l}\mathrm{RSD}^{1} \text { without } \\
\text { filter }\left(\mathrm{s}_{\mathrm{r}} 1\right) \\
\mathrm{g} / 100 \mathrm{~g}\end{array}$ & $\begin{array}{l}\mathrm{CV} \text { of } \\
\mathrm{s}_{\mathrm{r}} 1, \%\end{array}$ & $\begin{array}{l}\text { Repeatability } \\
\quad \text { limit } \mathrm{r} \\
\left(\mathrm{r}=2.8 \times \mathrm{s}_{\mathrm{r}} 1\right)\end{array}$ & $\begin{array}{l}\text { RSD with } \\
\text { filter }\left(\mathrm{s}_{\mathrm{r}} 2\right) \text {, } \\
\mathrm{g} / 100 \mathrm{~g}\end{array}$ & $\begin{array}{l}\mathrm{CV} \text { of } \\
\mathrm{s}_{\mathrm{r}} 2, \%\end{array}$ & $\begin{array}{l}\text { Repeatability } \\
\quad \text { limit } \mathrm{r} \\
\left(\mathrm{r}=2.8 \times \mathrm{s}_{\mathrm{r}} 1\right)\end{array}$ \\
\hline Grasses & 6 & $3.82^{\mathrm{a}}$ & $4.19^{\mathrm{b}}$ & 0.13 & 3.42 & 0.36 & 0.15 & 3.61 & 0.42 \\
\hline Wheat straws & 5 & $7.94^{\mathrm{a}}$ & $8.88^{\mathrm{b}}$ & $0.19 \dagger$ & 2.51 & 0.55 & $0.08 \ddagger$ & 0.94 & 0.23 \\
\hline Conventional corn silage & 12 & $2.32^{\mathrm{a}}$ & $2.84^{\mathrm{b}}$ & $0.18 \dagger$ & 8.06 & 0.52 & $0.06 \ddagger$ & 2.28 & 0.18 \\
\hline Brown midrib corn silage & 11 & $1.36^{\mathrm{a}}$ & $1.71^{\mathrm{b}}$ & 0.07 & 5.31 & 0.20 & 0.09 & 5.56 & 0.26 \\
\hline Alfalfas & 16 & $6.03^{\mathrm{a}}$ & $6.22^{\mathrm{b}}$ & 0.22 & 3.69 & 0.62 & 0.25 & 4.14 & 0.72 \\
\hline Immature grasses & 10 & $2.11^{\mathrm{a}}$ & $2.86^{\mathrm{b}}$ & 0.07 & 3.53 & 0.20 & 0.08 & 2.80 & 0.22 \\
\hline Feces & 9 & $6.18^{\mathrm{a}}$ & $7.32^{\mathrm{b}}$ & $0.23 \dagger$ & 3.72 & 0.64 & $0.06 \ddagger$ & 0.95 & 0.19 \\
\hline
\end{tabular}

$\overline{\mathrm{a}, \mathrm{b}}$ Values within a row with different superscripts differ $(P<0.05)$.

${ }^{1}$ Repeatability standard deviation.

$\dagger \ddagger$ Pairwise comparison for RSD of the procedures differ $(P<0.05)$. 
$0.06 \%$ for $\mathrm{ADF}$ and $\mathrm{ADL}$, respectively, and also reduced the variation in measurement of ADL in wheat straws and conventional corn silages. Small particles that form during the grinding step and the analytical procedure can be lost and compromise the values of both $\mathrm{ADF}$ and ADL among forage groups. This can be a problem when conventional sintered glass crucibles are used without a microfiber filter aid, which will alter the repeatability of the assays.

The use of the glass microfiber filters (934-AH) with small porosity is therefore recommended to increase recovery during the sequential $\mathrm{ADF}-\mathrm{ADL}$ procedure. Some degradation of the filter can occur during the $72 \% \mathrm{H}_{2} \mathrm{SO}_{4}$ treatment; however, test results indicated that the degradation did not affect the precision or recovery and could be managed through the use of blanks (results not shown). Most of this degradation occurred due to the physical mixing of the ADF and sulfuric acid with the Teflon stir rod. To decrease the chance of filter degradation, an alternative approach was evaluated. The sample was measured into a small beaker (50 to $100 \mathrm{~mL}$ ), soaked in excess $72 \% \mathrm{H}_{2} \mathrm{SO}_{4}$, stirred appropriately, and then filtered into crucibles with the microfiber glass filters. The results of this alternative procedure were consistent with the assay as described previously, with almost identical results (data not shown). If employing the alternative procedure it is suggested that the vacuum be applied slowly, allowing the sample time to sediment during the filtering and rinsing step and then applying the vacuum.

In summary, improved recoveries were achieved in the $\mathrm{ADF}$ and $\mathrm{ADL}$ assays with the use of the microfiber glass filters with a $1.5-\mu \mathrm{m}$ pore size inserted into the
Gooch crucible. The application of this filter aid improves the assays and restores the method to be consistent with the AOAC ADL method of Van Soest (1973).

\section{REFERENCES}

Besle, J. M., A. Cornu, and J. P. Jouany. 1994. Roles of structural phenylpropanoids in forage cell wall digestion. J. Sci. Food Agric. 64:171-190.

Cochran, R. C., E. S. Vanzant, and T. DelCurto. 1988. Evaluation of internal markers isolated by alkaline hydrogen peroxide incubation and acid detergent lignin extraction. J. Anim. Sci. 66:3245-3251.

Environmental Protection Agency. 1989. Asbestos Ban and Phase Out. Accessed March 13, 2011. http://www.epa.gov/asbestos/ pubs/ban.html.

Fahey, G. C., Jr., and H. G. Jung. 1983. Lignin as a marker in digestion studies: A review. J. Anim. Sci. 57:220-225.

Hatfield, R., and R. S. Fukushima. 2005. Can lignin be accurately measured? Crop Sci. 45:832-839.

Jung, H. J. G., V. H. Varel, P. J. Weimer, and J. Ralph. 1999. Accuracy of klason lignin and acid detergent lignin methods as assessed by bomb calorimetry. J. Agric. Food Chem. 47:2005-2008.

Mertens, D. R. 2002. Gravimetric determination of amylase-treated neutral detergent fiber in feeds with refluxing in beakers or crucibles: Collaborative study. J. AOAC Int. 85:1217-1240.

Udén, P. 2006. Recovery of insoluble fibre fractions by filtration and centrifugation. Anim. Feed Sci. Technol. 129:316-328.

Van Soest, P. J. 1973. Collaborative study of acid detergent fibre and lignin. J. Assoc. Off. Anal. Chem. 56:781-784.

Van Soest, P. J. 1994. Nutritional Ecology of the Ruminant. 2nd ed. Cornell Univ Press, Ithaca, NY.

Van Soest, P. J., and R. H. Wine. 1967. Use of detergents in the analysis of fibrous feeds. IV. determination of plant cell-wall constituents. J. Assoc. Off. Anal. Chem. 50:50-55.

Wernimont, G. T., ed. 1990. Use of Statistics to Develop and Evaluate Analytical Methods. Association of Official Analytical Chemists (AOAC), Arlington, VA.

Whatman. 2009. Whatman Limited, GE Healthcare, Piscataway, NJ. Accessed March 3, 2011. http://www.whatman.com/ References/934-AH\%20RTUGlassMicrofiberFiltersDataSheet FINAL\%2011.30.09LR.pdf. 